ARTICLE OPEN

\title{
Corrosion fatigue behavior of electron beam melted iron in
} simulated body fluid

\author{
Steffen Wackenrohr $\mathbb{1}^{1 凶}$, Christof Johannes Jaime Torrent $\mathbb{E}^{2}$, Sebastian Herbst ${ }^{1}$, Florian Nürnberger ${ }^{1}$, Philipp Krooss $\mathbb{E}^{2}$, \\ Christoph Ebbert ${ }^{3}$, Markus Voigt ${ }^{3}$, Guido Grundmeier ${ }^{3}$, Thomas Niendorf ${ }^{2}$ and Hans Jürgen Maier (iD)
}

Pure iron is very attractive as a biodegradable implant material due to its high biocompatibility. In combination with additive manufacturing, which facilitates great flexibility of the implant design, it is possible to selectively adjust the microstructure of the material in the process, thereby control the corrosion and fatigue behavior. In the present study, conventional hot-rolled (HR) pure iron is compared to pure iron manufactured by electron beam melting (EBM). The microstructure, the corrosion behavior and the fatigue properties were studied comprehensively. The investigated sample conditions showed significant differences in the microstructures that led to changes in corrosion and fatigue properties. The EBM iron showed significantly lower fatigue strength compared to the HR iron. These different fatigue responses were observed under purely mechanical loading as well as with superimposed corrosion influence and are summarized in a model that describes the underlying failure mechanisms.

npj Materials Degradation (2022)6:18; https://doi.org/10.1038/s41529-022-00226-4

\section{INTRODUCTION}

Additive manufacturing (AM) is of increasing importance in biomedicine technology due to the high design freedom and low-cost production of small series ${ }^{1}$. Moreover, it is also possible to specifically adapt the microstructure by adjusting the cooling rates and thermal gradients within the manufacturing process, thus changing the microstructural and mechanical properties ${ }^{2-4}$.

In addition to the pure mechanical properties resulting from the different microstructures, the corrosion behavior also needs to be specifically adapted to match the demands set by use in biodegradable implants ${ }^{5}$. For example, the corrosion behavior can be adjusted by varying the microstructure of the material ${ }^{6}$ or the surface morphology ${ }^{7-9}$. The number of studies addressing the corrosion behavior of additively manufactured structures is small. Yet, studies on the corrosion behavior of $316 \mathrm{~L}$ have already shown that pitting corrosion phenomena can be attributed to the surface porosity of the AM-manufactured structures ${ }^{10}$.

Depending on the location of an implant within the body, it might be subjected to pronounced cyclic loads during its lifetime. Defects caused by AM can significantly reduce the service life ${ }^{11-13}$. If defect formation can be avoided, the service life of AM manufactured components can be as long as those of conventionally manufactured components ${ }^{14}$. Studies on defect tolerance with respect to fatigue behavior of martensitic steels have shown that small sharp defects can be regarded as equivalent to a crack $^{15}$ and thus significantly shorten the fatigue life. Such defects can occur as a result of AM processes, for example, in the form of lack of fusion (LOF) ${ }^{16}$. In addition to the defects, the type and texture of the AM microstructure can significantly influence crack growth, and thus fatigue life ${ }^{17}$. If the microstructure is specifically designed to curtail crack nucleation or growth, the fatigue strength can even be increased compared to conventionally manufactured components, e.g., ref. ${ }^{18}$.

In addition to common biodegradable materials such as zinc or magnesium $^{19,20}$, there is also a need for other types of materials with better mechanical properties, such as iron ${ }^{21}$. Iron as an implant material has already been successfully investigated in several animal studies ${ }^{22}$. For instance, stents made of iron were tested on the coronary arteries of pigs ${ }^{23}$. Studies on white rabbits also showed positive results with regard to biocompatibility, but the stents featured too low degradation rates in the in vivo experiments to be used as a biodegradable implant material ${ }^{24}$. Various studies have shown promising approaches to increase the corrosion rates compared to pure iron by using special alloy systems. In particular, Fe-Mn based alloy systems show significantly increased corrosion rates in body fluids compared to pure iron $^{22,25,26}$. Tailored manufacturing processes and the associated microstructure design can also increase the degradation rates ${ }^{22}$. The influence of different manufacturing methods on the microstructure and mechanical properties was shown by Hufenbach et al. using an Fe-Mn-C(-S) alloy ${ }^{27,28}$. By microalloying with $\mathrm{S}$ and applying high cooling rates, a fine austenitic microstructure with small MnS precipitates could be achieved in the casting process, which led to an increase in yield strength and ultimate tensile strength and further accelerated the corrosion rates ${ }^{27}$. For the same alloy, it was shown that processing by selective laser melting (SLM) resulted in even better mechanical properties with respect to the strength properties. However, the corrosion rates in simulated body fluid (SBF) decreased compared to the cast condition due to a more homogeneous degradation mode ${ }^{28}$. Other iron-based biodegradable alloys and their corrosion rates are summarized in Zheng et al. $^{21}$. In addition to conducting degradation measurements based on weight loss or other methods such as optical coherence tomography ${ }^{29}$ it is important to investigate the effects of degradation on the fatigue behavior of the materials as carried in this study.

Another way to adapt the degradation rates is to adjust the microstructure only by the manufacturing process and the related process parameters. This has the advantage that the biocompatibility of the iron is not compromised by alloying elements.

\footnotetext{
${ }^{1}$ Institut für Werkstoffkunde (Materials Science), Leibniz Universität Hannover, An der Universität 2, 30823 Garbsen, Germany. ${ }^{2}$ Institut für Werkstofftechnik (Materials Science), Universität Kassel, Mönchebergstraße 3, 34125 Kassel, Germany. ${ }^{3}$ Institut für Technische Chemie (Technical Chemistry), Universität Paderborn, Warburger Straße 100,33098 Paderborn, Germany. ${ }^{凶}$ email: wackenrohr@iw.uni-hannover.de
} 
Approaches to microstructure design using equal channel angular pressing $(\mathrm{ECAP})^{30}$ or annealing as well as electroforming show promising results in increasing the corrosion rates of pure iron ${ }^{31}$. Another approach is the use of porous materials. It has already been shown that porous implants based on Fe0.8P exhibit good biocompatibility, but the degradation rate must be increased for application as bone substitutes ${ }^{32}$. However, the degradation rates can be significantly higher when the material is subjected to external cyclic loads, as has already been shown for AM manufactured porous pure iron ${ }^{33,34}$. However, these processes partially limit the possible designs of the implants.

The present study provides a possible solution to this problem. Commercially pure iron (cp Fe) processed by electron beam melting (EBM) is compared with conventionally hot rolled (HR) iron. The processing by EBM allows tailoring the microstructure, which in turn can be exploited to adjust the corrosion and degradation rate. EBM has become a standard AM process in recent years. In this process, a metal powder is selectively melted with an electron beam layer by layer. The process is carried out in a vacuum at high temperatures ${ }^{35}$. In this present study the microstructure, corrosion properties and fatigue properties of the $\mathrm{HR}$ iron and EBM iron are compared and discussed.

\section{RESULTS}

\section{Microstructures of hot rolled and of electron beam melted} iron

The microstructure of the two material states was analyzed by optical microscopy (Fig. 1) and electron backscatter diffraction (EBSD) (Fig. 2). The rolling and the building direction are indicated in the vertical direction. In Figs. 1 and 2, the difference in the average grain size ( $27 \mu \mathrm{m}$ for the EBM iron and $60 \mu \mathrm{m}$ for HR iron) is obvious. For both materials, a clear ferritic microstructure is present. The slightly darker appearing grains in Fig. 1 are due to the selective etching by alcoholic nitric acid (2\%). From the EBSD analysis in Fig. 2a (HR material) it becomes obvious, that the single grains show some small internal orientation deviation, i.e., the color coding in each grain varies more than in the compared EBM manufactured condition. However, the grain boundary map (not
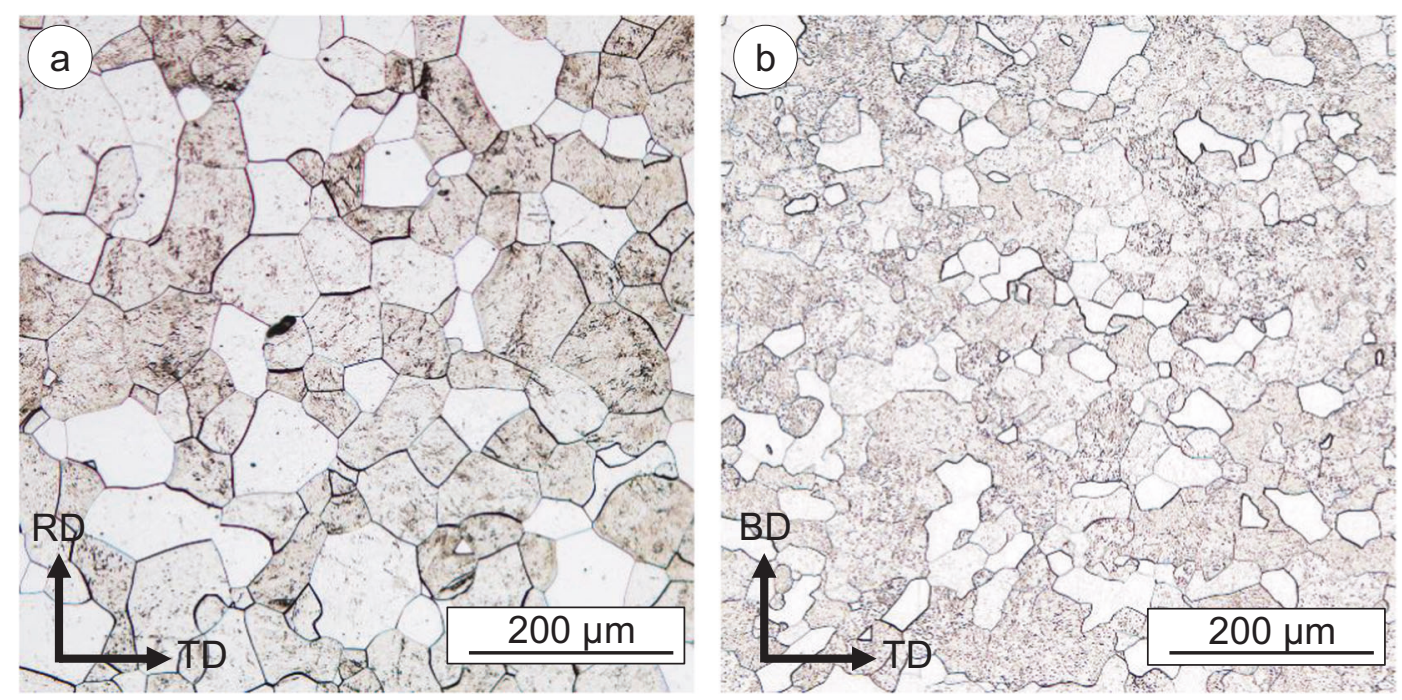

Fig. 1 Micrographs of the two material states. a HR iron, b EBM iron with rolling direction (RD), building direction (BD) and transverse direction (TD) marked in the figures.
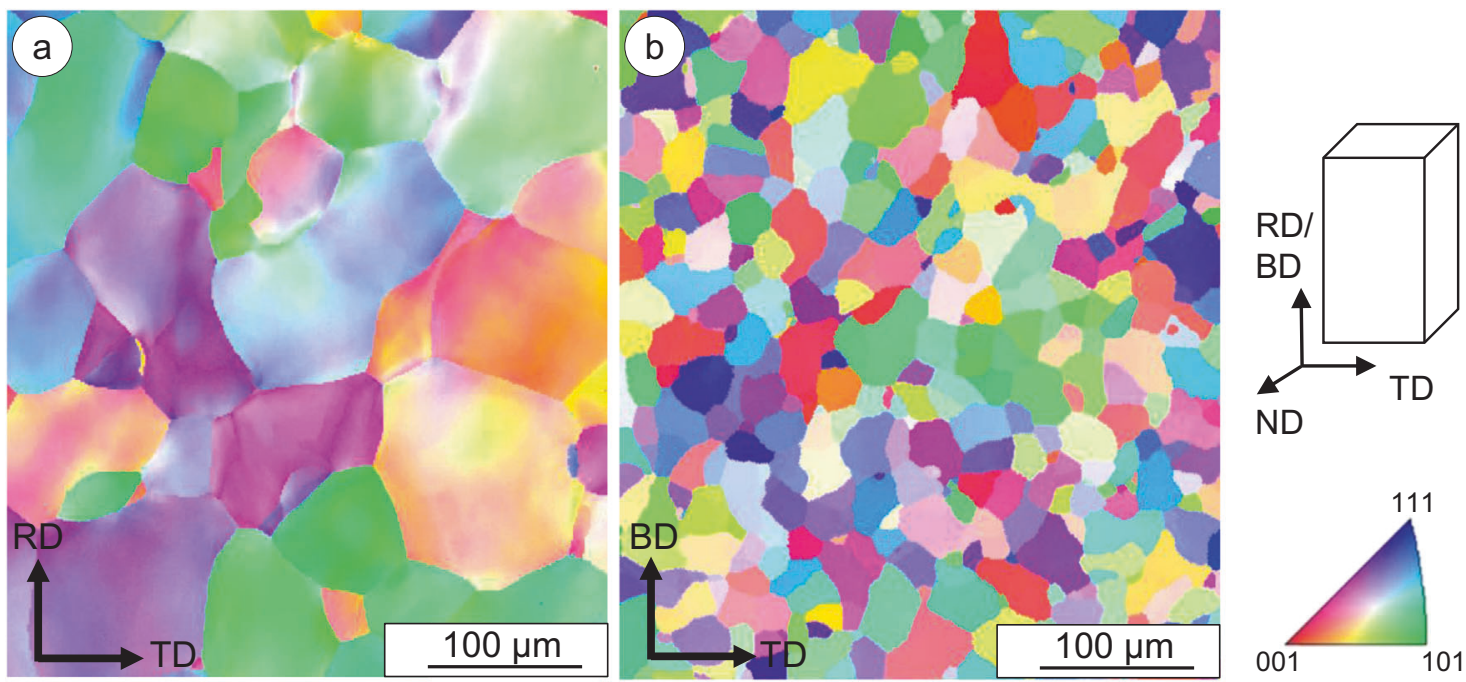

Fig. 2 EBSD orientation mappings with indication in normal direction (ND). a HR iron, b EBM iron. The rolling direction (RD), the building direction (BD) and transverse direction (TD) are marked in the figures. 

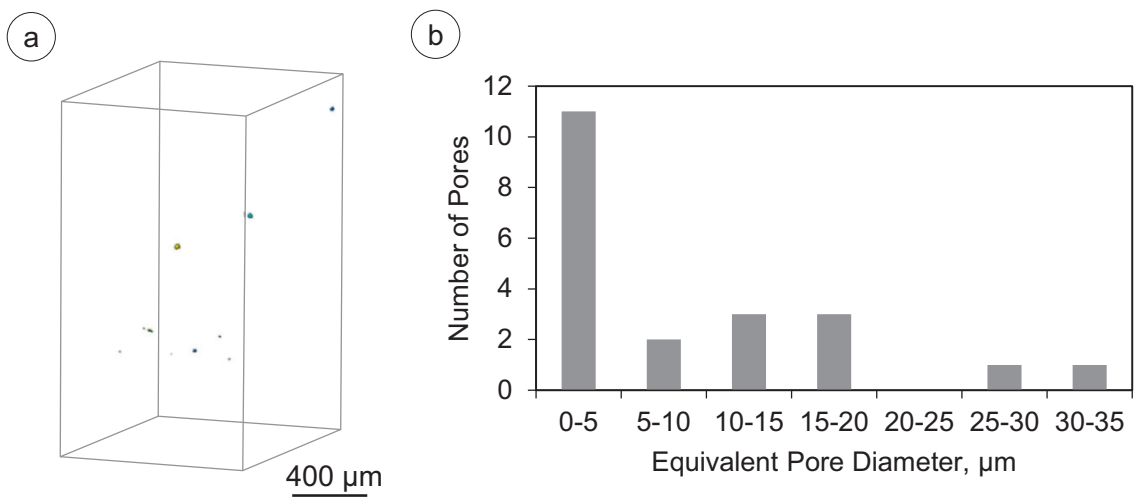

Fig. 3 Analysis of the porosity of the EBM iron. a $\mu$-CT scan of a randomly selected volume in the area of the sample seed of the EBM iron with the detected defect distribution, $\mathbf{b}$ histogram of the pore distribution in the probed volume (partly recompiled from ref. ${ }^{37}$ ).

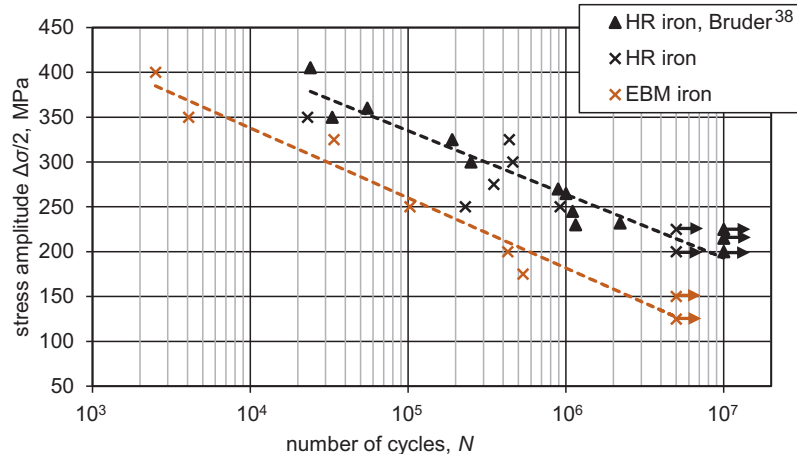

Fig. 4 S- $N$ curves for both material states. Fatigue life in rotating bending for HR iron (with data from refs. ${ }^{18,38}$ ) and EBM iron.

shown) reveals primary high angle grain boundaries (HAGB, misorientation angle $>15^{\circ 36}$ ) for both material states.

The porosity of the EBM-processed material was determined by analyzing a micro-computed tomography $(\mu-C T)$ scan. Since the specimen's edge layer can lead to imprecise measurements, the volume considered for data evaluation was inside the specimen and set to $\approx 3.35 \mathrm{~mm}^{3}$. The pores detected are depicted in Fig. 3a. The largest pore had a maximum length of $38.5 \mu \mathrm{m}$. The size distribution of the pores is shown in Fig. $3 \mathrm{~b}$ based on the equivalent pore diameters ${ }^{37}$. The equivalent pore diameter corresponds to the diameter that an ideal spherical pore would have with the same volume as the actually measured pore. Most of the pores were in the range of up to $5 \mu \mathrm{m}$. Based on all detected pores, the pore volume and the measured volume were set in relation, resulting in a relative density of $>99.99$ vol.- $\%$ for the EBM manufactured specimen. Here it has to be noted that other defects such as lack of fusion (LOF) are hardly detectable with the $\mu$-CT due to their low layer thickness.

\section{Fatigue behavior of HR and EBM iron}

The results of the fatigue tests are shown in Fig. 4 as $S-N$ curves. Samples that reached the defined endurance limit of $5 \times 10^{6}$ cycles and had not failed are marked by an arrow. For the HR iron, single samples reached the maximum number of cycles at $225 \mathrm{MPa}$. The fatigue strengths correspond well with the results for hot rolled ARMCO iron published by Bruder for similar rotating bending tests ${ }^{38}$. The $S-N$ curve of the EBM iron is shifted on average by $75 \mathrm{MPa}$ to lower values than the one obtained for the $\mathrm{HR}$ iron. Thus, the fatigue strength of $150 \mathrm{MPa}$ is significantly lower than the values reported for EBM iron in previous studies ${ }^{18}$. This demonstrates the large effects of the process conditions in the additive manufacturing and the resulting change in microstructure. The slightly larger difference between the two lines for high cycles can be attributed to small defects from the EBM process that often have a shortening effect on the fatigue life at a high number of cycles $^{39,40}$.

Figure 5 depicts scanning electron images of the fracture surfaces after the fatigue tests. These images were taken from areas remote from the surface, i.e., these are areas that are unaffected by surface defects. A complete overview of the fracture areas is shown in Fig. 5a for the HR iron and in Fig. $5 \mathrm{~d}$ for the EBM iron. The location for the detailed images is also indicated. The fatigue fracture represents about $90 \%$ of the total fracture area for both conditions. For the HR iron, distinct striations can be seen (Fig. $5 \mathrm{~b}$ ). In addition to the areas where fatigue crack propagation is evident, there is also pronounced plastic deformation on the specimen surface due to overload failure (Fig. 5c). In contrast, the EBM iron shows areas with LOF on the fracture surface (Fig. $5 f$ ) in addition to the typical fatigue striations (Fig. 5e).

The fracture surfaces of the EBM iron were further examined. Figure $6 a$ shows areas where LOF could be detected. The areas where LOF is present show dimensions of up to $100 \mu \mathrm{m} \times 400 \mu \mathrm{m}$. These LOF-areas were independent of the area of observation. LOF usually results from gas entrapment during $A M^{41}$, so that the defects are present in the inner parts of the specimens. After preparing the fatigue specimens by turning (described in detail in the "Methods" section), areas with LOF can be present in the surface layer where they can cause crack nucleation and additionally can promote crevice corrosion in the corrosion fatigue tests. Figure $6 \mathrm{~b}$ shows an area with LOF reaching the surface of a fatigued specimen.

\section{Microstructure after fatigue testing}

Figure 7 shows EBSD images of fatigued HR and EBM iron specimens after failure. The samples were cut such as to reveal the crack paths of the secondary fatigue cracks. The loading direction, which is equal to the rolling (HR iron) or build direction (EBM iron) is indicated in the figure. The areas shown have a distance of $\approx 200 \mu \mathrm{m}$ to the primary fatigue crack that led to the ultimate failure of the specimen. For the HR iron, the secondary fatigue crack with a length of about $400 \mu \mathrm{m}$ clearly propagated in a transcrystalline manner (Fig. 7a). In the wake of the crack, slight microstructural orientation deviations are visible, indicating local plastic deformation. For the crack propagation, no change in direction can be observed within the individual grains. The EBM iron also shows transcrystalline crack propagation, but the EBSD images revealed no local changes in crystallographic orientation in the wake of the crack (Fig. 7b). This is in accordance with the brittle features seen in the SEM images (Figs. $5 f$ and 6) and EBM iron shows several small fatigue cracks $(<100 \mu \mathrm{m})$ in the subsurface region of the specimen. Additionally, branching of the cracks can be observed. These fracture characteristics might indicate a 

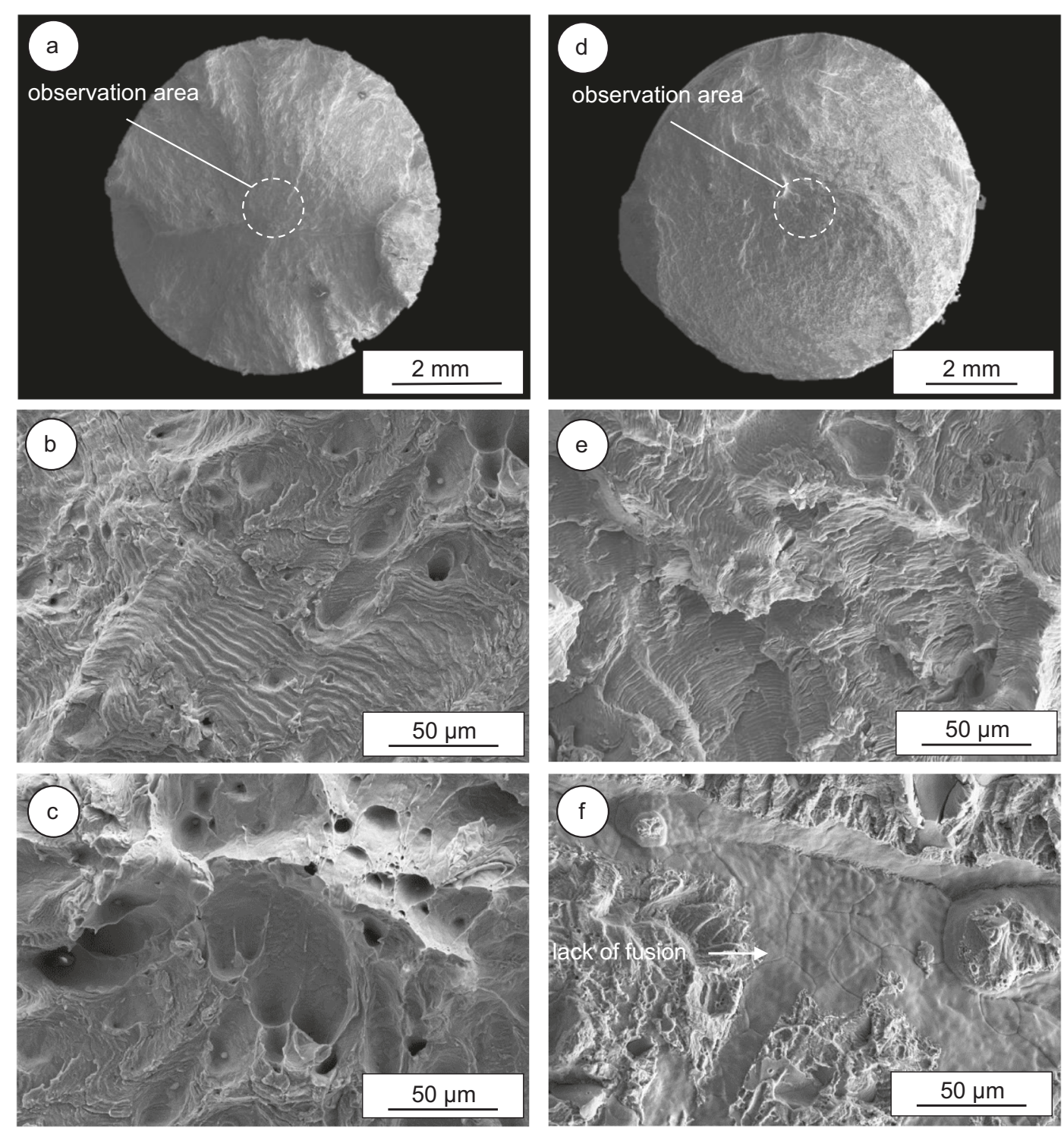

Fig. 5 Representative images of the fracture surface using secondary electron contrast mode. a Fatigued HR iron specimen $(250 \mathrm{MPa}$, $9.1 \times$ $10^{5}$ cycles) with an overview of the entire fracture area $\mathbf{b}$ striations and $\mathbf{c}$ areas of ductile fracture; fatigued EBM iron specimen ( $250 \mathrm{MPa}, 1 \times$ $10^{5}$ cycles) with $\mathbf{d}$ overview of the entire fracture area $\mathbf{e}$ striations and $\mathbf{f}$ areas with LOF.
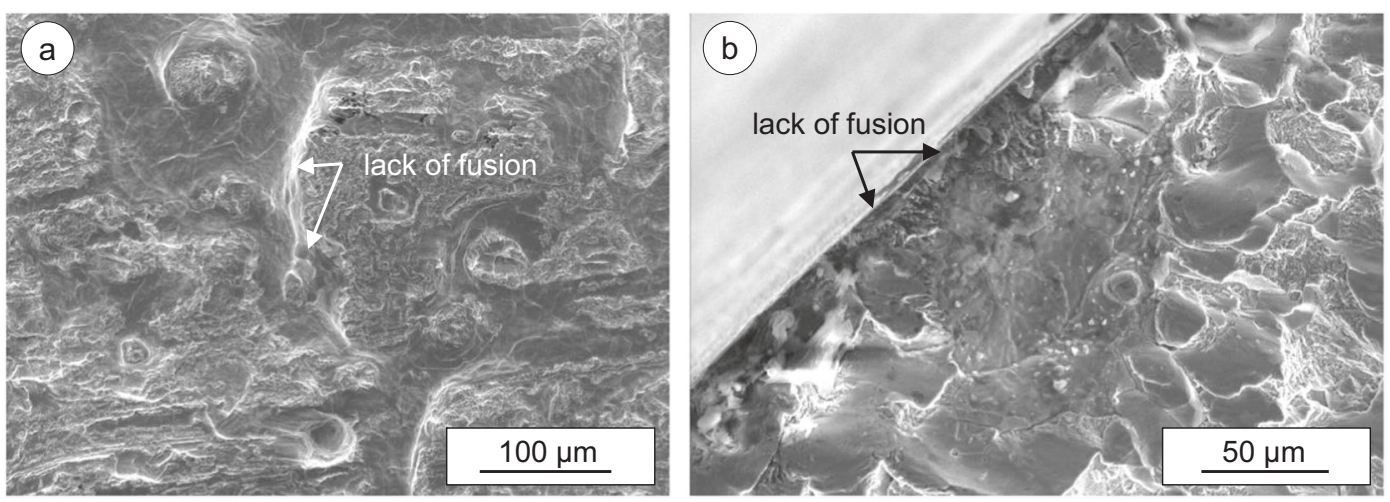

Fig. 6 Fracture surfaces with LOF defects. a Fatigued EBM specimen ( $400 \mathrm{MPa}, 2.5 \times 10^{3}$ cycles) with areas of LOF, b fatigued EBM specimen (325 MPa, $3.4 \times 10^{4}$ cycles) with areas of LOF at the specimens surface. 

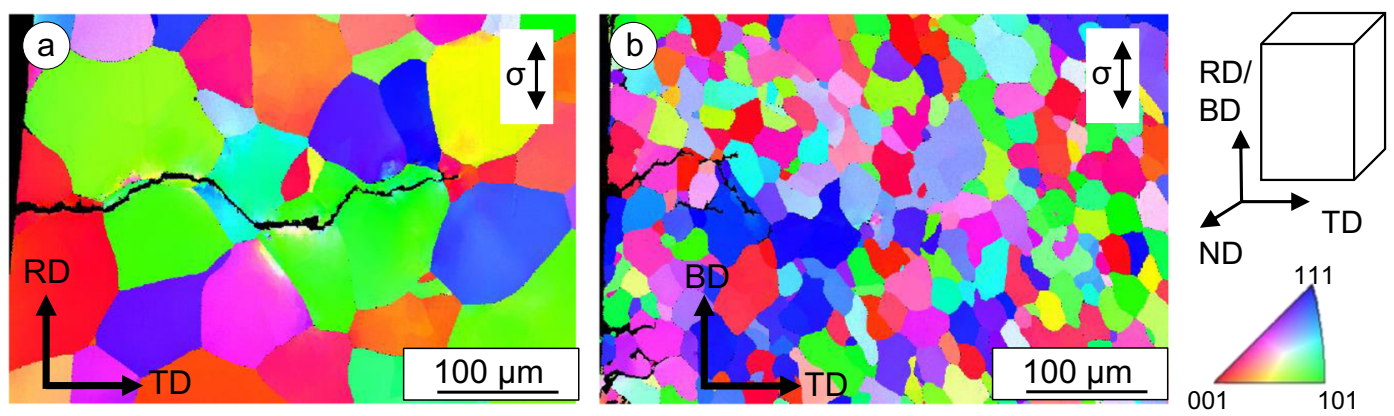

Fig. 7 EBSD orientation mappings of fatigued specimens with indication in normal direction (ND). a HR iron ( $250 \mathrm{MPa}, 2.3 \times 10^{5} \mathrm{cycles)}$ b EBM iron ( $250 \mathrm{MPa}, 1 \times 10^{5}$ cycles); see main text for details; the rolling direction (RD), the building direction (BD) and transverse direction (TD) are marked in the figures.

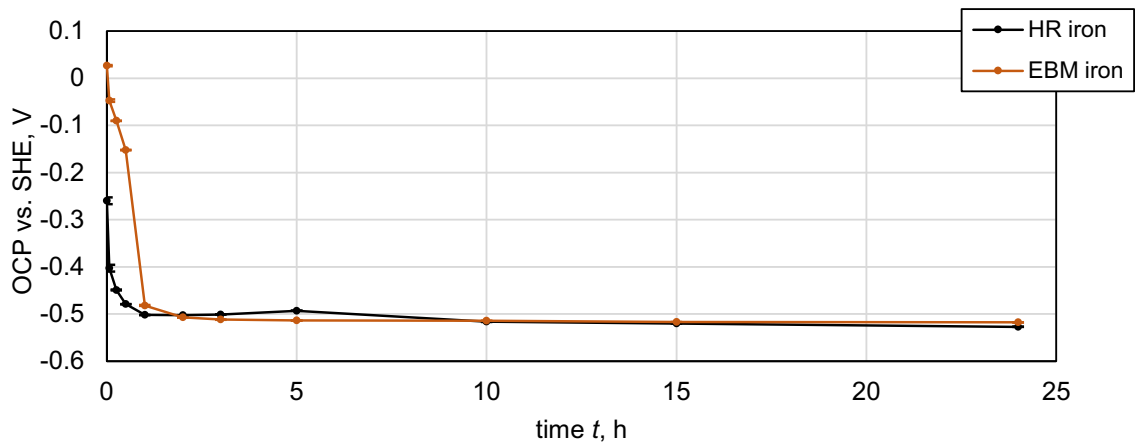

Fig. 8 OCP data. Shown for EBM iron and HR iron as a function of the immersion time in $\mathrm{m}$-SBF.

weaker bonding of the material within the matrix caused by process-related defects like pores or LOF. In addition, these defects will also locally change the stress state, which can promote a transcrystalline failure mode.

\section{Corrosion kinetics of HR and EBM iron in $\mathbf{m}-\mathrm{SBF}$}

The transient of the open circuit potential (OCP) for iron samples during immersion in modified simulated body fluid ( $m-S B F)$ is shown in Fig. 8. Both surfaces were etched in Nital solution for $5 \mathrm{~s}$ prior to the exposure to $\mathrm{m}-\mathrm{SBF}$. The transients show a substantial incubation time of about 40-50 min for the EBM sample while HR iron reaches the potential of actively corroding iron much faster. Electrochemical impedance spectroscopy (EIS) results of the samples exposed to $\mathrm{m}$-SBF are shown in Fig. $9 a, b$ in the form of Bode plots. Both samples show a time-dependent decrease of the impedance. However, the EBM processed sample shows higher initial impedance values in comparison to HR iron in agreement with the transient of the free corrosion potentials in Fig. 8. In agreement with the decreasing impedance values, the phase angle for low frequencies shifts to low values indicating a more and more dominating Ohmic resistance due to the initiation of interfacial corrosion reactions ${ }^{42-44}$.

In Fig. 10, the change in impedance values is plotted for a frequency of $0.1 \mathrm{~Hz}$. After a sharp drop in corrosion resistance in the initial phase of immersion for alloys, EBM iron shows a slightly higher corrosion resistance. However, for extended times of exposure this difference seems to diminish, most probably due to the formation of similar corrosion product layers.

From Fig. 10, both samples reach a nearly constant low frequency impedance value after about $3 \mathrm{~h}$. The extended incubation time for the EBM sample is clearly seen in the substantial drop in the low frequency impedance occurring after the onset of the experiment. Even after the incubation time, the corresponding impedance values at $0.1 \mathrm{~Hz}$ are higher for EBM iron in comparison to HR iron. The phase minimum at about $5 \mathrm{~Hz}$ for both samples indicates impedance values that are influenced by the double layer capacitance (cf. Fig. 9). Also in this region, the EBM sample shows higher impedance values and the phase minimum is at lower frequencies in comparison to the HR sample.

For a more thorough analysis of the EIS data, the corresponding spectra were fitted using an established equivalent circuit for porous surface layer coated metals, which is also often used for modelling corrosion layer covered alloy surfaces in corrosive media ${ }^{42-44}$. To take into account a non-uniform interface, the capacitance is exchanged by a constant phase element, $C P E^{42}$. The measured spectra could be fitted well with this equivalent circuit. The equivalent circuit fitting the corrosion film is shown schematically in Fig. 11.

The results of the modelling are shown in Table $1 \mathrm{a}, \mathrm{b}$. In agreement with the qualitative analysis of the impedance at $0.1 \mathrm{~Hz}$, the calculated pore resistance vales reveal that the EBM sample shows initially less corrosion activity leading to the already discussed incubation time. However, for extended immersion times the sum of pore and charge transfer resistance values tends to be rather similar which might indicate the contribution of the barrier effect of the formed corrosion scales at the $\mathrm{m}$-SBF/iron interface.

After the EIS studies, the samples were rinsed with Millipore water and dried in a stream of nitrogen. This process led to a removal of loosely adhering corrosion products and thereby allowed for the electron spectroscopy of the metal interface.

X-ray photoelectron spectroscopy (XPS analysis) was then used to quantify the formed surface composition in comparison to polished sample. The corresponding compositions are shown in Table 2 and the relevant Fe2p, as well as O1s spectra, are depicted in Fig. 12a-d and Fig. 13a-d. The compositions as measured by XPS did not show significant changes in the surface chemistry of both iron samples after the immersion at OCP (see Table 2). The increase in the oxygen to iron ratio indicates a surface oxidation process. In addition, minor changes could be attributed to the 

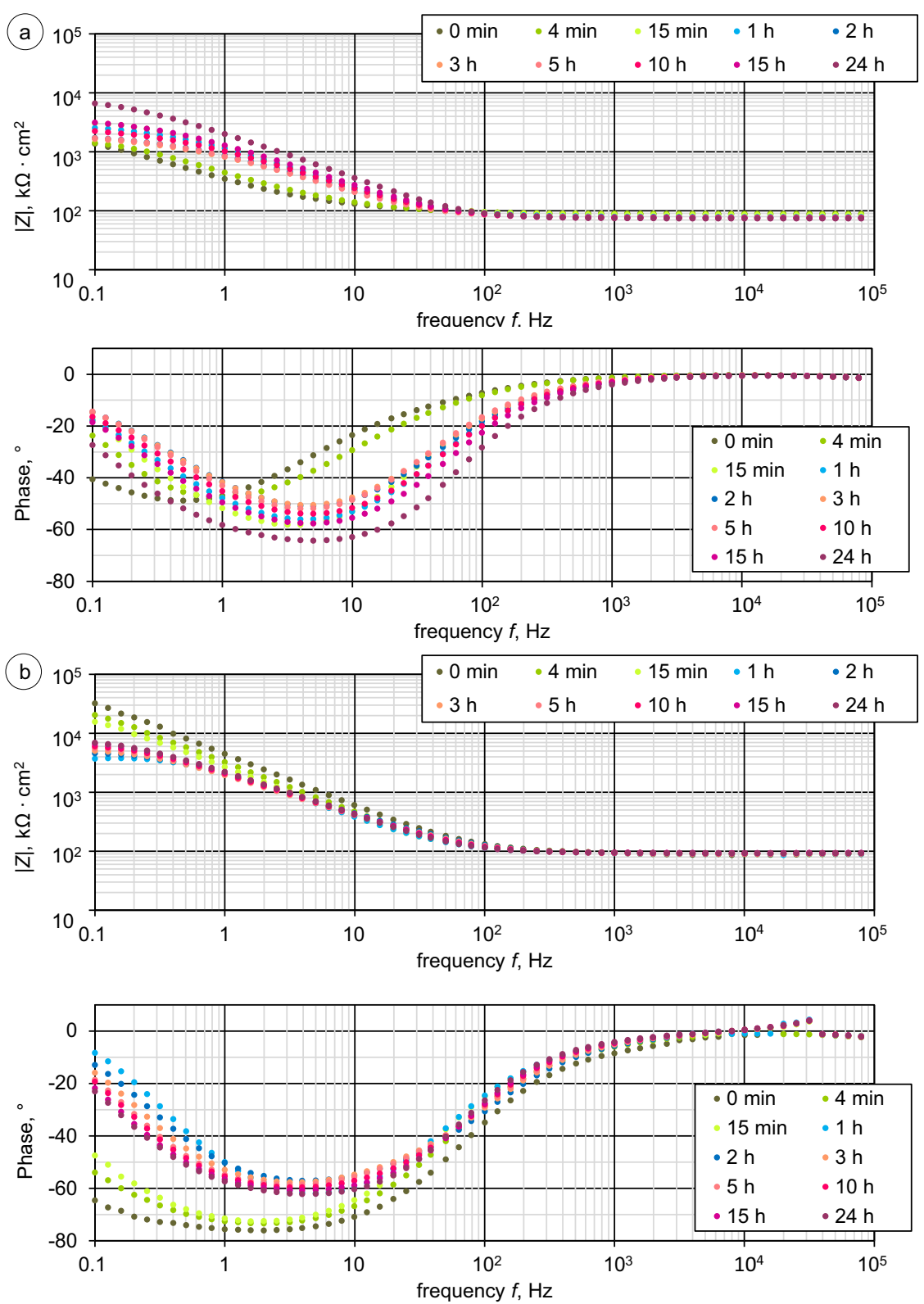

Fig. 9 Evolution of EIS data. Shown for a HR iron and b EBM iron upon immersion in m-SBF solution.

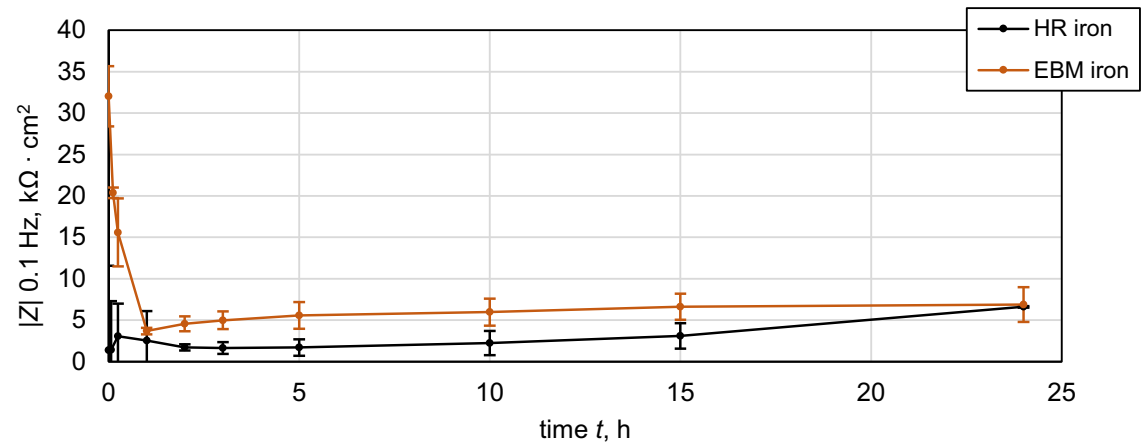

Fig. 10 Impedance values. Shown for both material states at $0.1 \mathrm{~Hz}$ as a function of the immersion time in m-SBF. 
adsorption from $\mathrm{m}$-SBF electrolyte and the surface preparation (polishing, etching in Nital $\left(\mathrm{HNO}_{3}\right) /$ methanol)).

However, the analysis of the Fe2p and O1s element spectra (see Figs. 12, 13) showed a change in the contribution of oxidation states within the surface oxide film and the formation of oxyhydroxides in all cases. The fitting of the Fe $2 p$ peaks and the contribution of the underlying metallic iron could be assigned to the peak at $706.8 \mathrm{eV}$ and the oxidation states of iron in the passive film were fitted to the literature ${ }^{45,46}$.

Not surprisingly, the contribution of Fe ${ }^{\text {III }}$ is significantly increased for both HR iron and EBM iron after immersion in $\mathrm{m}$-SBF in comparison to the Nital etched state. In addition, the XPS data of the $\mathrm{Fe} 2 p$ peak indicate that the formed surface layer is slightly thicker for the EBM iron sample as the ratio of the oxidic to metallic contribution is decreased from $26.4 \%$ to $11.4 \%$ for HR iron and from $24.9 \%$ to $8.8 \%$ for EBM iron. According to Grosvenor et al. the respective oxide layer thickness can be calculated ${ }^{47}$, however, the complexity of mixed oxide states and additional adventitious carbon only allows a rather qualitative estimation of the related

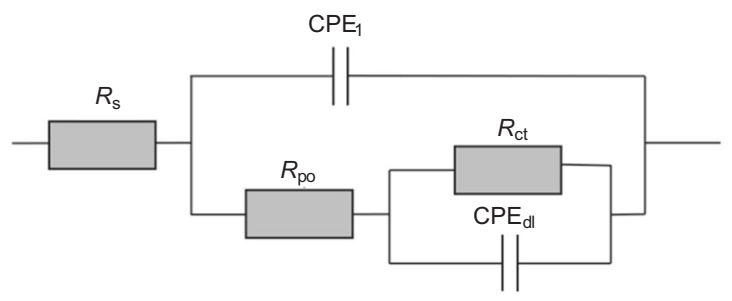

Fig. 11 Equivalent circuit of the corrosion film. Describing the covered surface of the Fe-substrates immersed in $\mathrm{m}$-SBF. thickness changes. An increase of an oxide layer thickness from 2.5 $(+/-0.2) \mathrm{nm}$ to $3.5(+/-0.2) \mathrm{nm}$ was estimated.

The 01s data shown in Fig. 13 indicate that the surface film after the immersion in $\mathrm{m}$-SBF consists of $\mathrm{FeOOH}$ as indicated by the $\mathrm{OH}$-contribution at $531.5 \mathrm{eV}$.

\section{Fatigue behavior in $\mathbf{m}-\mathrm{SBF}$}

The results of the fatigue tests under the superimposed corrosive influence of $\mathrm{m}-\mathrm{SBF}$ are shown in Fig. 14. For comparison, the results under pure mechanical load from Fig. 4 are included. The test duration is also indicated on the $x$-axis. For both material conditions, the increasing corrosion effect upon lowering the stress amplitude, i.e., increasing test duration, is reflected in the significantly shorter fatigue life compared to purely mechanical fatigue testing. In the range of stress amplitudes tested, no EBM iron specimen reached the endurance limit of $5 \times 10^{6}$ cycles. Samples that reached the endurance limit are marked by an arrow.

In Fig. 14, there is a significant difference in the slopes of the trend lines of the corrosion fatigue tests. Especially for the EBM iron, the trend line is significantly steeper compared to HR iron. By contrast, for the fatigue tests under purely mechanical loading, the trend lines of the two material states have nearly identical slopes (cf. Fig. 4). At first glance, this contradicts the results of the corrosion studies where the EBM iron showed a higher corrosion resistance (cf. Fig. 10). However, this discrepancy can be explained by the presence of pores and LOF, which result in crevice corrosion leading to a shortening of fatigue life. Especially at a high number of cycles, these defects have an increasingly shortening effect on the fatigue life over the increasing test duration $^{39,40}$.

\begin{tabular}{|c|c|c|c|c|c|c|c|c|}
\hline Time & $R_{\mathrm{po}}\left(\Omega \cdot \mathrm{cm}^{2}\right)$ & $R_{\mathrm{ct}}\left(\Omega \cdot \mathrm{cm}^{2}\right)$ & $R_{\mathrm{s}}\left(\Omega \cdot \mathrm{cm}^{2}\right)$ & CPE 1 & a 1 & CPE dl & a dl & Goodness of fit \\
\hline \multicolumn{9}{|c|}{ (a) HR iron } \\
\hline $0 \mathrm{~min}$ & 85 & 2599 & 88 & $4.2 \times 10^{-4}$ & 0.79 & $4.2 \times 10^{-4}$ & 0.74 & $9.5 \times 10^{-5}$ \\
\hline $4 \min$ & 262 & 1460 & 88 & $3.8 \times 10^{-4}$ & 0.81 & $1.9 \times 10^{-4}$ & 0.84 & $1.2 \times 10^{-4}$ \\
\hline $2 \mathrm{~h}$ & 736 & 1257 & 76 & $1.5 \times 10^{-4}$ & 0.85 & $2.9 \times 10^{-4}$ & 0.57 & $1.3 \times 10^{-4}$ \\
\hline $3 \mathrm{~h}$ & 412 & 1534 & 76 & $1.5 \times 10^{-4}$ & 0.86 & $2.4 \times 10^{-4}$ & 0.53 & $1.2 \times 10^{-4}$ \\
\hline $5 \mathrm{~h}$ & 548 & 1418 & 76 & $1.5 \times 10^{-4}$ & 0.86 & $2.3 \times 10^{-4}$ & 0.56 & $1.3 \times 10^{-4}$ \\
\hline $10 \mathrm{~h}$ & 424 & 2262 & 75 & $1.0 \times 10^{-4}$ & 0.89 & $1.7 \times 10^{-4}$ & 0.59 & $9.4 \times 10^{-5}$ \\
\hline $15 \mathrm{~h}$ & 367 & 3491 & 75 & $7.2 \times 10^{-5}$ & 0.93 & $1.3 \times 10^{-4}$ & 0.63 & $1.1 \times 10^{-4}$ \\
\hline $7 \mathrm{~min}$ & 19930 & 27680 & 92 & $6.2 \times 10^{-6}$ & 0.87 & $6.8 \times 10^{-12}$ & 0.64 & $5.1 \times 10^{-4}$ \\
\hline $15 \mathrm{~min}$ & 8884 & 20000 & 92 & $7.3 \times 10^{-5}$ & 0.87 & $1.8 \times 10^{-6}$ & 1.00 & $5.9 \times 10^{-4}$ \\
\hline $1 \mathrm{~h}$ & 2296 & 1865 & 91 & $7.3 \times 10^{-5}$ & 0.87 & $2.4 \times 10^{-5}$ & 1.00 & $8.7 \times 10^{-4}$ \\
\hline $2 \mathrm{~h}$ & 5000 & 435 & 89 & $9.6 \times 10^{-5}$ & 0.78 & $1.5 \times 10^{-4}$ & 0.99 & $8.8 \times 10^{-4}$ \\
\hline $3 \mathrm{~h}$ & 1684 & 3933 & 90 & $7.5 \times 10^{-5}$ & 0.83 & $3.7 \times 10^{-5}$ & 0.94 & $4.7 \times 10^{-4}$ \\
\hline $5 \mathrm{~h}$ & 3066 & 3980 & 90 & $1.0 \times 10^{-4}$ & 0.79 & $4.4 \times 10^{-7}$ & 0.59 & $9.2 \times 10^{-4}$ \\
\hline $10 \mathrm{~h}$ & 1259 & 5870 & 92.5 & $5.8 \times 10^{-5}$ & 0.88 & $5.3 \times 10^{-5}$ & 0.79 & $3.7 \times 10^{-4}$ \\
\hline $15 \mathrm{~h}$ & 1571 & 6623 & 93.2 & $5.6 \times 10^{-5}$ & 0.89 & $5.6 \times 10^{-5}$ & 0.78 & $3.4 \times 10^{-4}$ \\
\hline $24 \mathrm{~h}$ & 5786 & 2794 & 91.4 & $8.9 \times 10^{-5}$ & 0.82 & $1.1 \times 10^{-10}$ & 0.12 & $1.2 \times 10^{-3}$ \\
\hline
\end{tabular}




\section{DISCUSSION}

EBM processing has a significant influence on the microstructure of pure iron. The microstructure is considerably finer compared to HR iron (cf. Fig. 1). In both cases, the grains are primarily separated by HAGB. The formation of a certain grain morphology and texture is strongly related to mechanical as well as thermal history.

Table 2. Surface composition in at.-\% of polished and immersed HR iron and EBM iron samples as measured by XPS.

\begin{tabular}{lllllll}
\hline At.-\% & O1s & N1s & C1s & Fe2p & P2p & S2p \\
\hline HR iron polished & 37.0 & - & 46.0 & 17.0 & - & - \\
HR iron immersed & 49.1 & 0.7 & 34.4 & 12.1 & 1.7 & 2.0 \\
EBM iron polished & 45.2 & - & 36.1 & 18.7 & - & - \\
EBM iron immersed & 52.2 & - & 34.9 & 12.9 & - & - \\
\hline
\end{tabular}

(a)

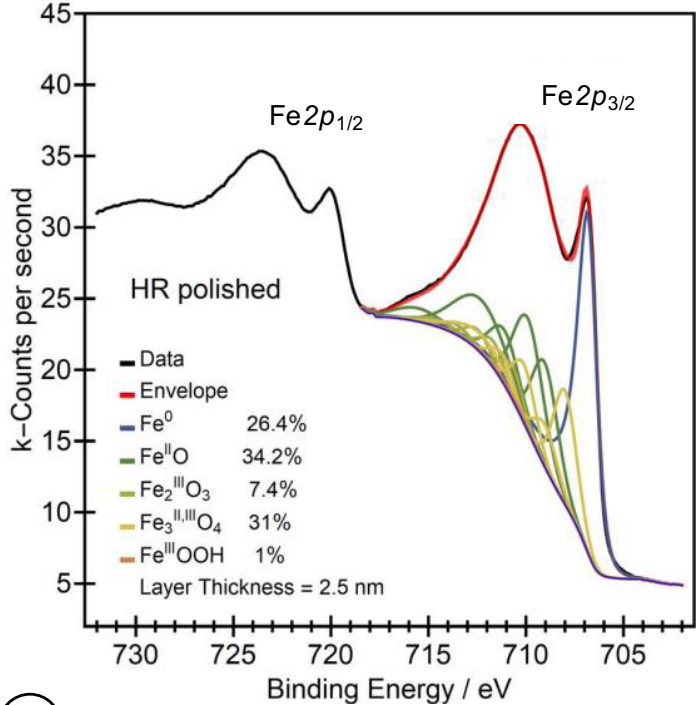

(C)

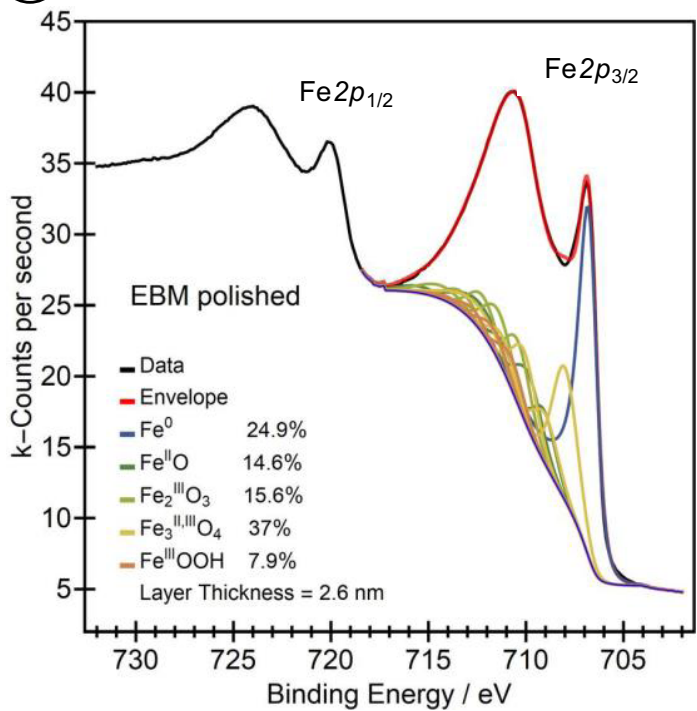

Although the details of hot rolling conditions were not provided by the supplier, it is apparent that there has been enough driving force for recrystallization resulting in the structure shown in Fig. 2a. Further, the deviations shown in Fig. 2a can be traced back to dislocations induced in the hot rolling process. In contrast, the reason for the observed grain size and morphology resulting from the EBM process can be found in the cyclic thermal treatment that the material experiences while being processed. In this context, a very effective grain refining mechanism as a result of multiple solid to solid phase transformations has been described in detail for selective laser melting $(S L M)^{48}$ as well as for $E^{2} M^{3,49}$. The repeated phase transformations are specific for powder bed AM and can result in a transition from initially columnar solidified grains into a fine and globular structure. However, the finer microstructure did not have the expected ${ }^{50}$ positive effect on fatigue strength (Fig. 4). In the EBM and HR iron employed the present study, the fatigue cracks proceeded in a transcrystalline manner. Usually, this reduces the fatigue crack growth rate, e.g., Vaidya et al. ${ }^{51}$. As depicted in Fig. 7, in the wake of the crack, grain orientation variations can be detected in the HR material

(b)

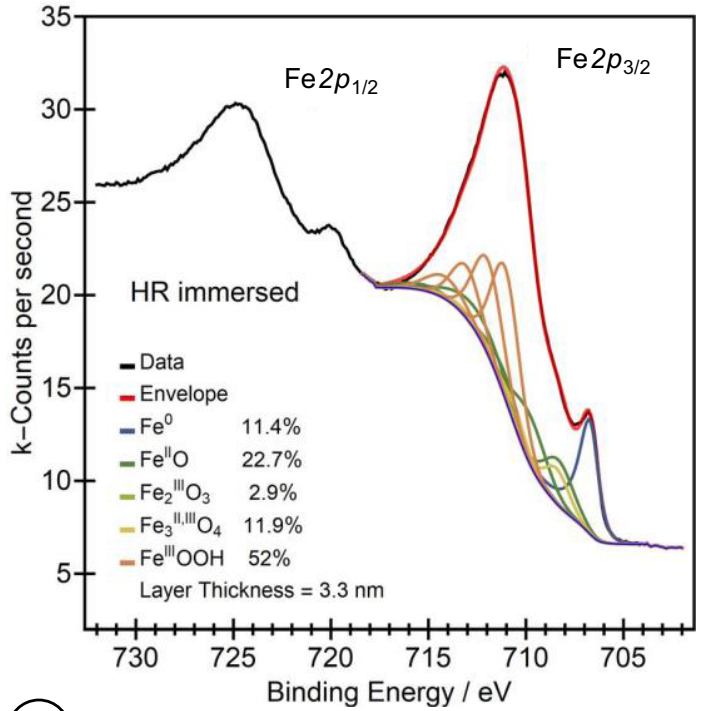

(d)

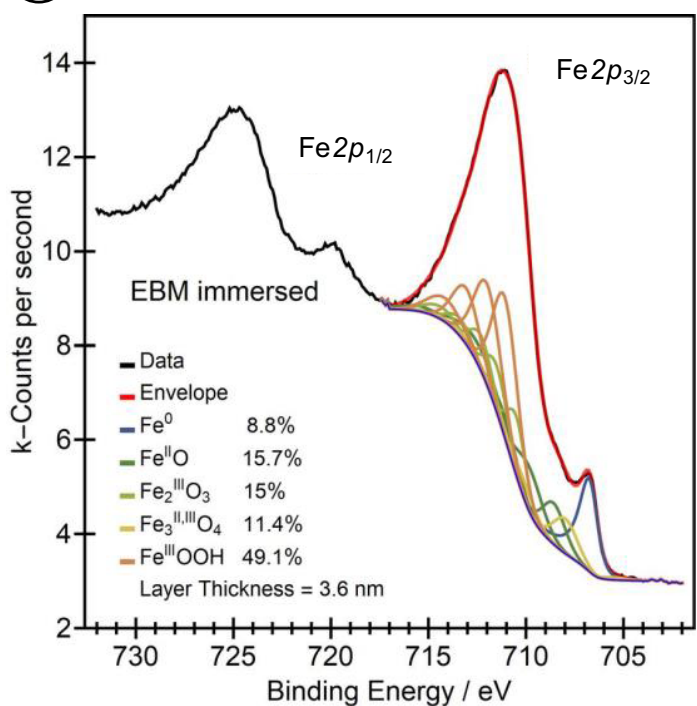

Fig. 12 Fe2p element spectra of as-prepared (polished, etched) samples in comparison to the surface states after 24-h immersion in m-SBF. Shown for $\mathbf{a}, \mathbf{b}$ HR iron and c, d EBM iron. 


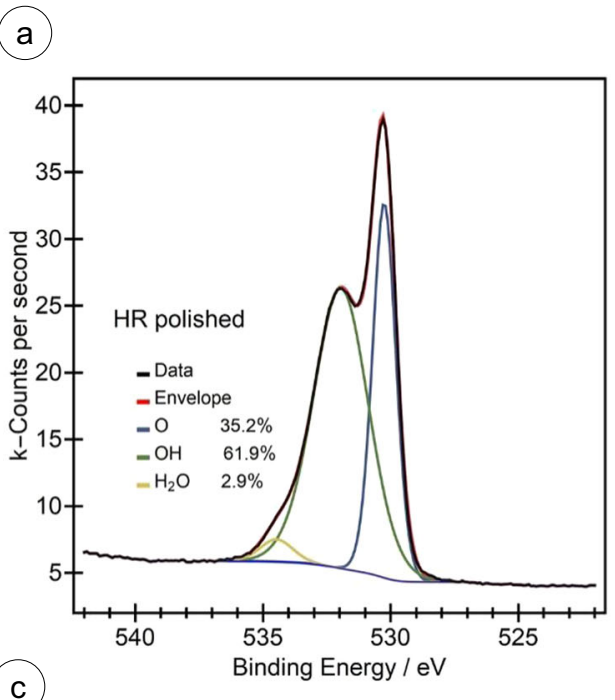

(b)
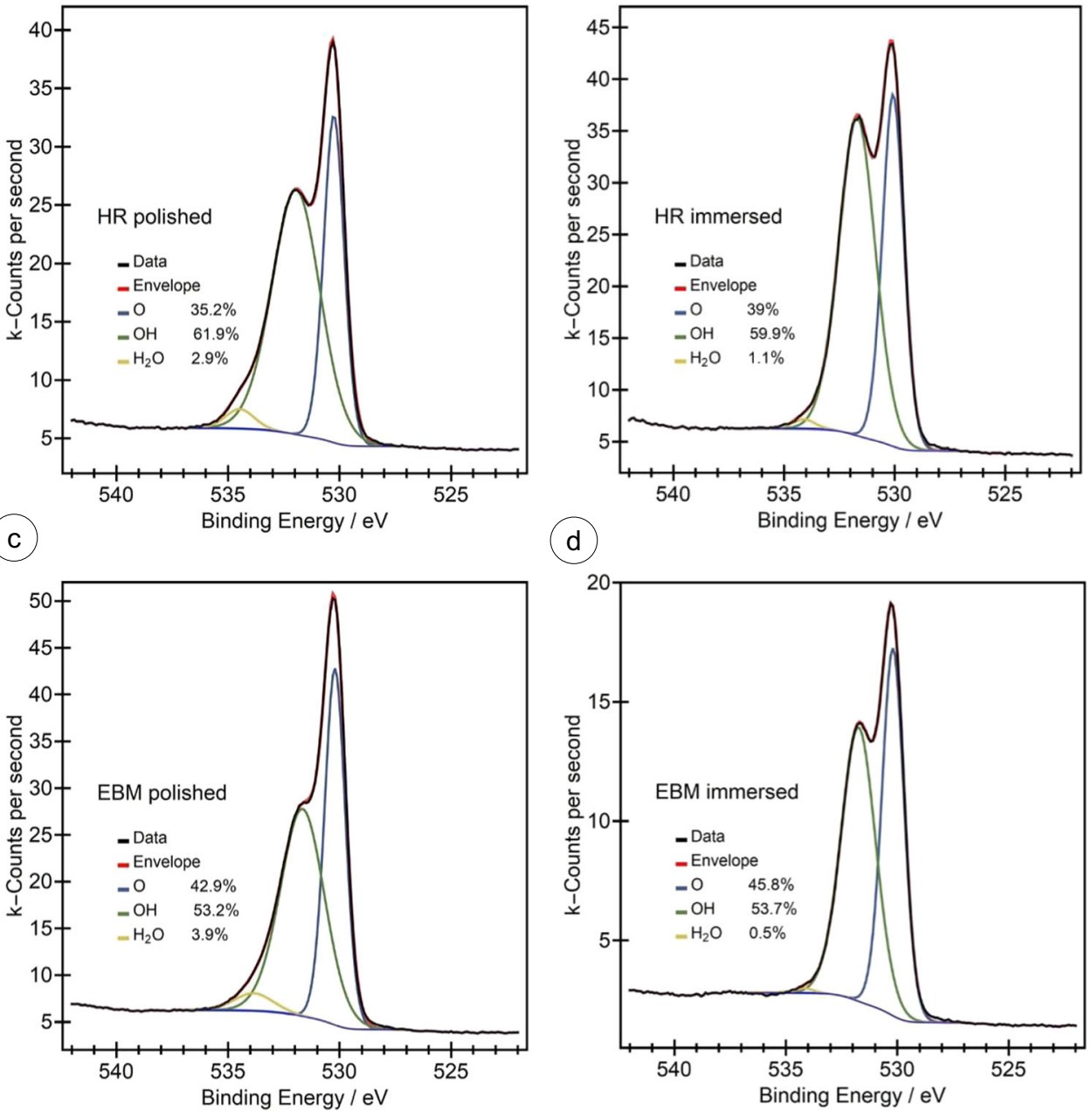

Fig. $1301 \mathrm{~s}$ element spectra of as-prepared (polished, etched) samples in comparison to the surface states after 24-h immersion in $\mathbf{m}$-SBF. Shown for $\mathbf{a}, \mathbf{b}$ HR iron and $\mathbf{c}$, $\mathbf{d}$ EBM iron.

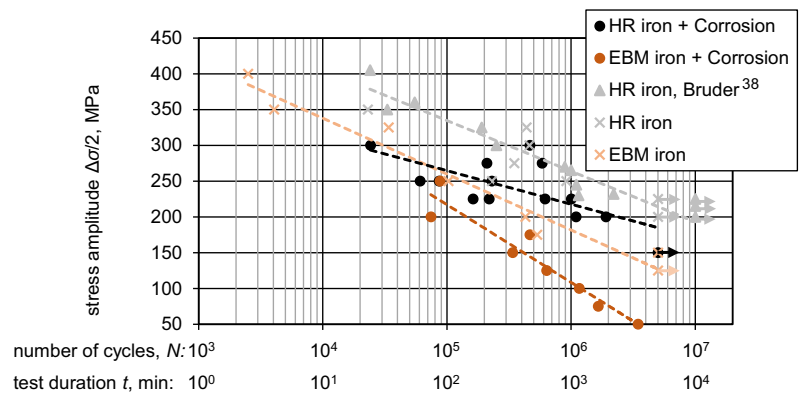

Fig. $14 \mathrm{~S}-\mathrm{N}$-curves obtained from corrosion fatigue tests conducted in $\mathbf{m}$-SBF. Both material states are shown in comparison with fatigue tests under purely mechanical load (cf. Fig. 4).

condition, but not in the EBM manufactured counterpart. One can expect that during crack propagation, a substantial amount of energy is dissipated upon crack propagation in the HR iron, due to the coarser grained microstructure. This argument is in line with results from previous fatigue investigations ${ }^{18}$, in which additively manufactured iron characterized by a coarse grained microstructure with a high fraction of LAGB was used. The latter resulted a higher fatigue resistance and the material featured high hardness and yield strength values, all of which were mainly attributed to the contribution of LAGBs to the Hall-Petch relation. The EBM iron microstructure presented herein is finer grained. Thus, local stress peaks, particularly near process-induced defects, could not be reduced by local microstructure deformation.

Another aspect to be considered when classifying the lower fatigue strengths of the EBM iron compared to the HR iron (Fig. 4) is related to potential defects caused by EBM processing. The maximum pore diameter found was $38.5 \mu \mathrm{m}$. Fatigue studies on additively manufactured material have shown that these pores, caused by process-related weaknesses such as insufficient melting of the material or gas entrapments, often act as initiation site for failure, which in turn significantly reduces the fatigue strength $^{11,13,14}$. Thus, the fracture surfaces of the samples were examined in detail to detect defects relevant for failure. LOF could be detected on all EBM iron fracture surfaces (Figs. $5 f$ and 6a). On the fracture surfaces, the LOF show dimensions of up to $100 \times$ $400 \mu \mathrm{m}$. Due to the small layer thickness of these defects in the material matrix, these cannot be resolved by the $\mu$-CT measurements. As described in the results, LOF can be exposed at the specimen surface during the manufacturing process (Fig. $6 \mathrm{~b}$ ) and thus promote crevice corrosive effects. The formation of LOF and related defects can be significantly influenced by the hatch strategy as well as the heating and related cooling rates ${ }^{52}$. Tammas-Williams et al. reported that the volume fraction of gas 
pores and LOF could be reduced by increasing the energy densities of the electron beam ${ }^{41}$. The decrease in the defect volume is attributed to the larger melt pool, which allows larger overlaps, and thus an intensified re-melting of the single layers. This also increases the chance for trapped gas to escape ${ }^{41}$. For similar processes in AM, such as powder bed fusion, models already exist to predict the porosity on the basis of the prevailing process parameters ${ }^{53}$. These models can be used in upcoming studies to tailor the fatigue and corrosion behavior based on the porosity.

EBM and HR iron differ in their corrosion behavior in $\mathrm{m}-\mathrm{SBF}$. Overall, the EBM iron shows a slightly lower corrosion rate. The lower corrosion rate of the EBM variant is attributed to the smaller grain size. This is in line with studies by Nie et al., in which a significantly higher corrosion resistance could be shown for nanocrystalline pure iron processed by ECAP compared to commercial pure iron ${ }^{30}$. The data available in the literature on the effect of grain size on corrosion resistance were reviewed by Ralston et al. $^{54}$. It was found for various materials that grain refinement generally leads to increased corrosion resistance. This is mainly attributed to an improved formation of the passivation film and adhesion as a result of the higher grain boundary density. Nevertheless, direct evidence is still lacking in the literature. In fact, the corrosion properties must always be investigated individually, since these depend not only on the material but also strongly on the actual environmental conditions ${ }^{54}$.

The fatigue tests in $\mathrm{m}$-SBF solution showed that the fatigue strength of EBM is significantly reduced (Fig. 14). The main reason for the reduction of the fatigue strength appear to be surface defects promoting the corrosive influence of the $\mathrm{m}$-SBF and the associated earlier crack initiation. The considerably stronger influence of corrosion on the fatigue behavior of EBM iron can be explained by the higher number of defects in the material. In fact, a variety of LOF-areas were detected on the fracture surfaces of the EBM iron. These defects are exposed at the surface by the turning process and the following electropolishing during manufacturing of the fatigue specimens. At the specimen's surface, these LOF are additionally opened by the applied mechanical loads, and this should promote crevice corrosion effects. The observed branching (cf. Fig. 7b) can additionally amplify these effects as this additionally impairs the electrolyte exchange with the environment. Therefore, the protective passivation film of the EBM iron cannot be formed in these areas and the crevice corrosion effects lead to significantly reduced fatigue strength of the EBM iron. In previous investigations of corrosion behavior, Chou et al. processed a Fe-30 Mn alloy via AM. Starting from a much higher open porosity of $36.3 \%$, a significantly higher corrosion rate could be shown compared to pure iron ${ }^{55}$. The porosities determined for the EBM iron in the current study are significantly lower $(<0.01 \%)$. Thus, it can be assumed that porosity has no pronounced influence on the corrosion behavior without an applied mechanical load, which explains the higher corrosions resistance without mechanical load (cf. Fig. 10). However, in combination with a mechanical load, even the low porosities and the areas with LOF can have a significant influence on the corrosion rates and can lead to an early failure.

The mechanisms during corrosion fatigue are described and summarized in the following model, which is schematically depicted in Fig. 15. For the development of the inhibiting layer of corrosion products, the model is based on the corrosion behavior of pure iron ${ }^{56}$ and the models proposed by J. Li et al. and $Z$. Li et al. for magnesium alloys ${ }^{57,58}$. The HR iron and the EBM iron initially differ only in terms of the size of the microstructural features and the defects. The EBM iron has the finer microstructure and single defects are present in the bulk and at the surface of the specimen. Prior to the fatigue test, an ultra-thin oxide film is present on both materials. The iron released in $\mathrm{m}$-SBF is oxidized to $\mathrm{Fe}^{3+}$ by dissolved oxygen and later forms oxyhydroxides and phosphates in m-SBF. During the corrosion fatigue tests, the EBM iron forms a thicker homogeneous protective layer due to the finer grain size resulting from the manufacturing process ${ }^{54}$. Similar effects are already known for aluminum alloys or biodegradable alloys like zinc-magnesium ${ }^{59,60}$.

The cyclic mechanical load in the rotating bending test results in the highest loads on the surface of the specimens. Plastic deformation in favorably oriented grains causes a continuous break-up of the inhibiting protective layer. This, in turn, leads to enhanced corrosion on the newly exposed surfaces resulting from the mechanical loading. Similar failure models that take into account the break-up of the oxide layer were described by Teoh ${ }^{61}$. By the formation of slip bands breaking through the protective layer, a rapid repassivation is prevented there and bare metal is exposed at the surface ${ }^{61}$. In the present scenario, defects present in the matrix play a key role in this process because of the locally increased stress. Thus, in the EBM material, crack nucleation and growth are more rapid as defects near the surface promote crack nucleation and at a later stage the fatigue cracks can interact with the process-induced internal defects. Thus, the presence of defects clearly outweighs the expected positive effect of a reduced grain size on fatigue life.

The main results can be summarized as follows:

1. The microstructure of HR and EBM iron differs significantly and influences the corrosion and fatigue behavior.

2. The expected positive effects of the finer microstructure obtained by EBM-processing on fatigue life are outweighed by the processing-induced defects such as pores and lack of fusion.

3. The slightly lower corrosion rate of the EBM samples in $m-S B F$ might partly counterbalances the effects of the process-induced defects such that the overall fatigue life of the EBM samples is still acceptable for many implant applications.

4. EBM iron appears to be an attractive biodegradable material as its mechanical properties and corrosion behavior can be tailored by processing without the need for further alloying elements.

\section{METHODS}

\section{Materials and chemical composition}

For the production of the EBM specimens, bars of the HR iron were obtained from Allied Metals Corp. (ALLIED METALS CORPORATION, Auburn Hills, Michigan) and atomized via Electrode Induction-melting Gas Atomization (TLS-TECHNIK GmbH, Bitterfeld, Germany). Subsequently, the powder material was processed with an Arcam A2X EBM machine (ARCAM $A B$, Mölndal, Sweden). The process parameters applied are detailed $\mathrm{in}^{18}$. A $50 \mathrm{~mm} \times 50 \mathrm{~mm}$ built plate was used, which lead to an increase of the overall process temperature. Thus, repeated $a \leftrightarrow \gamma$ phase transformations occur upon EBM, resulting in the fully recrystallized microstructure. Table 3 shows the chemical composition of the HR and EBM manufactured iron, determined by Revierlabor Essen $\mathrm{GmbH}$. Within the material composition, no significant differences could be determined between HR iron and EBM iron.

\section{Microstructural investigations}

For the microstructural investigations, the surfaces were ground and then electrolytically polished with Bühler A2. A scanning electron microscope

\begin{tabular}{|c|c|c|c|c|c|c|c|}
\hline & $\mathrm{Al}$ & $\mathrm{Mn}$ & 0 & $N$ & $S$ & C & $\mathrm{Fe}$ \\
\hline HR iron & 0.008 & 0.03 & 0.0166 & 0.005 & 0.002 & $<0.005$ & balance \\
\hline EBM iron & $<0.005$ & $<0.01$ & 0.017 & $<0.002$ & $<0.002$ & $<0.005$ & balance \\
\hline
\end{tabular}


Prior to fatigue test:

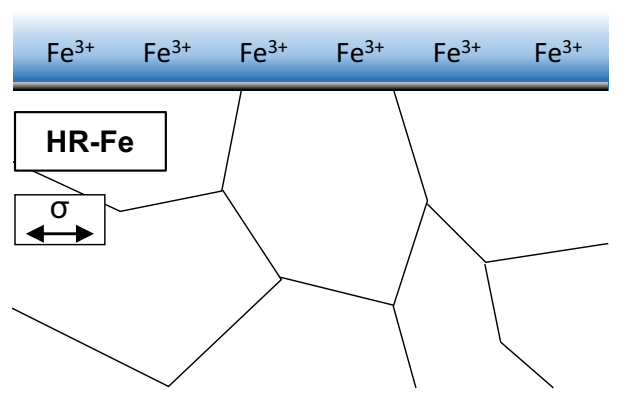

During fatigue test:

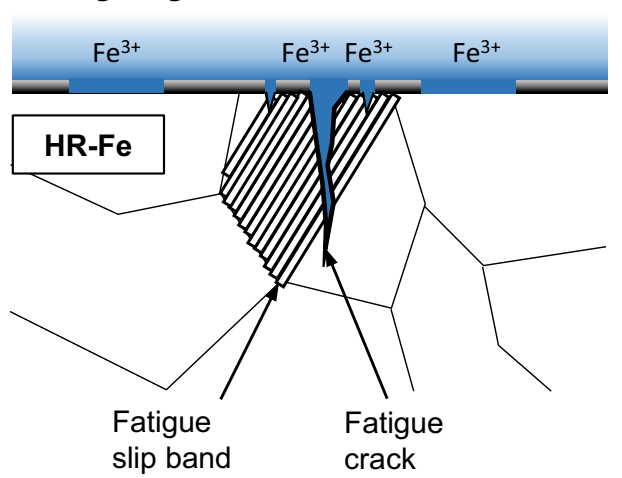

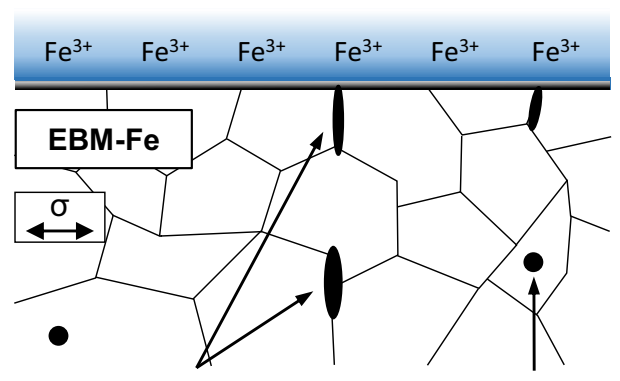

Lack of Fusion

Pores

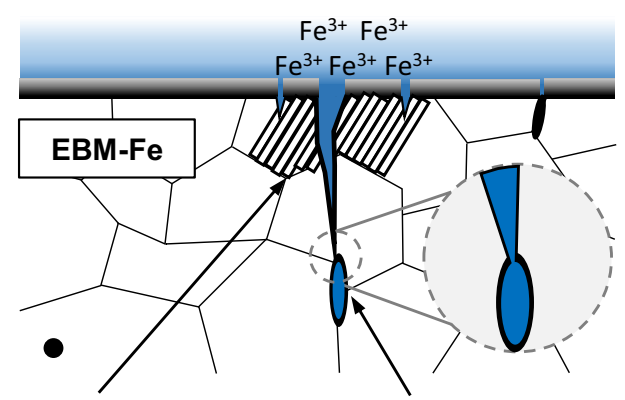

Fatigue Enhanced fatigue crack growth slip band and corrosion at defects

\section{Grain boundaries}

$\square$ Oxide Layer: $\mathrm{Fe}_{2}\left(\mathrm{OH}_{3}\right)$

$\mathrm{m}-\mathrm{SBF}$

Fig. 15 Description of the corrosion fatigue behavior for both material states. Fatigue model for HR iron and EBM iron taking the microstructure and passivation in $\mathrm{m}-\mathrm{SBF}$ into account.

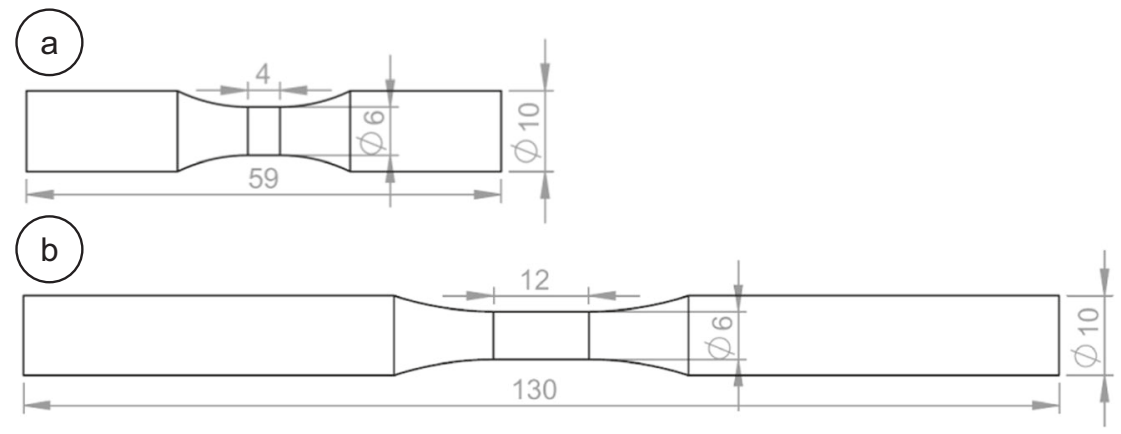

Fig. 16 Specimen geometries for fatigue testing. a EBM iron b HR iron.

(SEM, Zeiss Ultra Plus; ZEISS, Oberkochen, Germany) equipped with an electron backscatter diffraction detector was employed at a nominal voltage of $20 \mathrm{kV}$ and a step size of $1.25 \mu \mathrm{m}$ for higher resolution work. The grain orientation data were evaluated with TSL OIM software (Version 7). For the investigations of the crack propagation within the microstructure, the surface was only mechanically polished in several steps down to a $1 \mu \mathrm{m}$ diamond finish.

$\mu-C T$ was conducted with a Zeiss Xradia Versa 520 operating at an acceleration voltage of $140 \mathrm{kV}$ and a current of $10 \mathrm{~mA}$. Avizo software (version 9.4) was used for the reconstruction. As the voxel size was about $1.85 \mu \mathrm{m}^{3}$, pores with a diameter smaller than $4 \mu \mathrm{m}$ were excluded from evaluation. The latter is considered to be legitimate, since previous studies demonstrated very high ductility and the finer pores may therefore not be relevant to damage ${ }^{18}$. The fracture surfaces of the fatigue specimens were examined with a SEM, Zeiss Supra 55 VP scanning electron microscope.

\section{Fatigue testing}

Figure 16 shows the specimens employed for fatigue testing. The dimensions of the EBM specimens were significantly reduced in length in order to save material. Both geometries were designed according to DIN
50113 for rotating bending tests. The specimens were turned from the manufactured bars with a nominal diameter of $13 \mathrm{~mm}$. Hence, a $3.5 \mathrm{~mm}$ thick layer was removed circumferentially in the gauge length $(6 \mathrm{~mm}$ diameter) of the EBM iron specimens. Thus, all surface defects caused by the EBM processing were removed.

For the fatigue tests a Zwick Roell 200 tC $\odot$ was used. The specimens were loaded with a constant bending moment along the specimen's axis, leading to a rotating bending stress on the surface layer with stress amplitudes ranging from $50 \mathrm{MPa}$ to $400 \mathrm{MPa}$. The stress amplitude locally exceeded the tensile strength of pure iron of about $250 \mathrm{MPa}$. Hence, some stress relief by plastic flow in the surface region of the specimen occurred. The endurance limit was determined at $N=5 \times 10^{6}$, resulting in a maximum test duration of $83.3 \mathrm{~h}$ with the selected rotational speed of $n=1000 \mathrm{~min}^{-1}$.

Two different test series were carried out, one purely mechanically and one with additional influence of the $\mathrm{m}$-SBF media. In the corrosion fatigue tests, the specimens were continuously wetted with the m-SBF solution by constantly dripping it onto the specimen. The rotation resulted in a constant liquid film on the entire measuring length of the specimen. The flow rate of the fluid was $Q=150 \mathrm{ml} \mathrm{h}^{-1}$. The temperature of the $\mathrm{m}-\mathrm{SBF}$ during the fatigue testing was $25^{\circ} \mathrm{C}$. 


\begin{tabular}{|c|c|c|}
\hline Reagents & Purity & Amount \\
\hline $\mathrm{NaCl}$ & $>99.5 \%$ & $5.403 \mathrm{~g}$ \\
\hline $\mathrm{NaHCO}_{3}$ & $>99.5 \%$ & $0.504 \mathrm{~g}$ \\
\hline $\mathrm{Na}_{2} \mathrm{CO}_{3}$ & $>99.5 \%$ & $0.426 \mathrm{~g}$ \\
\hline $\mathrm{KCl}$ & $>99.5 \%$ & $0.225 \mathrm{~g}$ \\
\hline $\mathrm{K}_{2} \mathrm{HPO}_{4} \cdot 3 \mathrm{H}_{2} \mathrm{O}$ & $>99.0 \%$ & $0.230 \mathrm{~g}$ \\
\hline $\mathrm{MgCl}_{2} \cdot 6 \mathrm{H}_{2} \mathrm{O}$ & $>98.0 \%$ & $0.311 \mathrm{~g}$ \\
\hline $0.2 \mathrm{M}-\mathrm{NaOH}$ & - & $100 \mathrm{ml}$ \\
\hline $\begin{array}{l}\text { HEPES (4-(2-hydroxyethyl)-1- } \\
\text { piperazineethanesulfonic acid) }\end{array}$ & $>99.9 \%$ & $17.892 \mathrm{~g}$ \\
\hline $\mathrm{CaCl}_{2}$ & $>95.0 \%$ & $0.293 \mathrm{~g}$ \\
\hline $\mathrm{Na}_{2} \mathrm{SO}_{4}$ & $>99.0 \%$ & $0.072 \mathrm{~g}$ \\
\hline $1.0 \mathrm{M}-\mathrm{NaOH}$ & - & $\fallingdotseq 5 \mathrm{ml}$ \\
\hline
\end{tabular}

\section{Electropolishing of the specimens and usage of $\mathrm{m}$-SBF solution}

Before the fatigue tests, the parallel and the radial surfaces of the fatigue specimens were electropolished to obtain a consistent and smooth specimen surface. The electrolyte used was K1 Part A + B from ATM $\odot$ based on ethanol and perchloric acid. By electropolishing a surface layer of about $150 \mu \mathrm{m}$ was removed. In this way, all machining-induced artefacts during specimen preparation were eliminated. The roughness after electropolishing was determined with a confocal microscope to be $R_{\mathrm{a}} \leq$ $0.1 \mu \mathrm{m}$ for both conditions $\left(R_{\mathrm{a}}\right.$ is the arithmetical mean deviation of the assessed profile).

The composition of the modified simulated body fluid ( $m-S B F)$ solution applied during the in-vitro fatigue tests is described in detail in Oyane et al. The $\mathrm{m}$-SBF solution was designed to match the composition of blood plasma, except for the concentration of $\mathrm{HCO}^{3-}$ to account for the influence of calcites present ${ }^{62}$. The composition of the $\mathrm{m}-\mathrm{SBF}$ is given in Table 4.

\section{Electrochemical analysis}

For electrochemical corrosion studies a three-electrode setup with a saturated $\mathrm{Ag} / \mathrm{AgCl}$ electrode (Red Rod, Radiometer Analytical) as reference $\left(\mathrm{E}(\mathrm{Ag} / \mathrm{AgCl})=+0.186 \mathrm{~V}_{\mathrm{SHE}}\right)$, the sample as working electrode and a graphite counter electrode were used. Samples were ground, mirror polished, cleaned in an ultrasonic ethanol bath and finally etched in Nital solution ( $3 \% \mathrm{HNO}_{3} /$ methanol at room temperature (RT)) for $5 \mathrm{~s}$. The $\mathrm{m}-\mathrm{SBF}$ solution tempered at $37^{\circ} \mathrm{C}$ served as electrolyte. Etching with Nital allows for the removal of the mechanically deformed surface near region and adsorbed contaminations while a reproducible ultra-thin surface oxide film is formed prior to the immersion in $\mathrm{m}$-SBF.

The electrochemical measurements were performed with a potentiostat interface 1000 (Gamry Instruments). The impedance spectra were recorded in a frequency range from 0.1 to $10^{5} \mathrm{~Hz}$ with an amplitude of $\pm 20 \mathrm{mV}$. The evolution of the impedance spectra was studied over 24 hours of immersion. Prior to each EIS measurement the corresponding OCP value was recorded.

\section{XPS analysis}

The surface chemical composition of the iron surface before and after immersion was analyzed using an UHV-XPS (ESCA+ facility, Oxford Instruments, Taunusstein, Germany). The system had a base pressure of lower than $5.0 \times 10^{-10} \mathrm{mbar}$. All spectra were measured using monochromatic Al Ka irradiation (1486.7 eV). A take-off angle of $30^{\circ}$ with respect to the surface was chosen for all spectra. The calibration was performed using the $\mathrm{C} 1 \mathrm{~s}$ signal (at $284.6 \mathrm{eV}$ ) of adventitious carbon as internal reference. A background according to Shirley was used. The survey spectra were measured with a pass energy of $100 \mathrm{eV}$, the detail spectra of Fe2p with one of $20 \mathrm{eV}$. The resolution of the surveys was $0.5 \mathrm{eV}$, that of the element spectra $0.1 \mathrm{eV}$.

\section{DATA AVAILABILITY}

The data that support the findings of this study are available from the corresponding author upon request.

\section{CODE AVAILABILITY}

Code sharing not applicable to this article as no code was generated or analyzed during the current study.

Received: 17 June 2021; Accepted: 8 February 2022;

Published online: 08 March 2022

\section{REFERENCES}

1. Frazier, W. E. Metal additive manufacturing: a review. J. Mater. Eng. Perform. 23, 1917-1928 (2014)

2. Collins, P. C., Brice, D. A., Samimi, P., Ghamarian, I. \& Fraser, H. L. Microstructural control of additively manufactured metallic materials. Annu. Rev. Mater. Res. 46, 63-91 (2016).

3. Körner, C. Additive manufacturing of metallic components by selective electron beam melting - a review. Int. Mater. Rev. 61, 361-377 (2016).

4. Helmer, H., Bauereiß, A., Singer, R. F. \& Körner, C. Grain structure evolution in Inconel 718 during selective electron beam melting. Mater. Sci. Eng. A 668, 180-187 (2016).

5. Kamachimudali, U., Sridhar, T. M. \& Raj, B. Corrosion of bio implants. Sadhana $\mathbf{2 8 ,}$ 601-637 (2003).

6. Murr, L. E. Open-cellular metal implant design and fabrication for biomechanical compatibility with bone using electron beam melting. J. Mech. Behav. Biomed. Mater. 76, 164-177 (2017).

7. Chi, G., Yi, D. \& Liu, H. Effect of roughness on electrochemical and pitting corrosion of Ti-6Al-4V alloy in $12 \mathrm{wt} . \% \mathrm{HCl}$ solution at $35^{\circ} \mathrm{C}$. J. Mater. Res. Technol. $\mathbf{9}$, 1162-1174 (2020).

8. Gravier, J., Vignal, V. \& Bissey-Breton, S. Influence of residual stress, surface roughness and crystallographic texture induced by machining on the corrosion behaviour of copper in salt-fog atmosphere. Corros. Sci. 61, 162-170 (2012).

9. Seo, M. J. I. et al. Haeng Influence of surface roughness on the corrosion behavior of Alloy 690TT in PWR primary water. Nucl. Eng. Des. 280, 62-68 (2014).

10. Sander, G. et al. On the corrosion and metastable pitting characteristics of $316 \mathrm{~L}$ stainless steel produced by selective laser melting. J. Electrochem. Soc. 164, C250-C257 (2017).

11. Hrabe, N., Gnäupel-Herold, T. \& Quinn, T. Fatigue properties of a titanium alloy (Ti-6Al-4V) fabricated via electron beam melting (EBM): Effects of internal defects and residual stress. Int. J. Fatigue 94, 202-210 (2017).

12. Leuders, $\mathrm{S}$. et al. On the mechanical behaviour of titanium alloy TiAl6V4 manufactured by selective laser melting: fatigue resistance and crack growth performance. Int. J. Fatigue 48, 300-307 (2013).

13. Romano, S. et al. Fatigue properties of AlSi10Mg obtained by additive manufacturing: defect-based modelling and prediction of fatigue strength. Eng. Fract. Mech. 187, 165-189 (2018).

14. Brandl, E., Heckenberger, U., Holzinger, V. \& Buchbinder, D. Additive manufactured AlSi10Mg samples using selective laser melting (SLM): Microstructure, high cycle fatigue, and fracture behavior. Mater. Des. 34, 159-169 (2012).

15. Schönbauer, B. M. \& Mayer, H. Effect of small defects on the fatigue strength of martensitic stainless steels. Int. J. Fatigue 127, 362-375 (2019).

16. Du Plessis, A., Yadroitsava, I. \& Yadroitsev, I. Effects of defects on mechanical properties in metal additive manufacturing: a review focusing on X-ray tomography insights. Mater. Des. 187, 108385 (2020).

17. Riemer, A. et al. On the fatigue crack growth behavior in $316 \mathrm{~L}$ stainless steel manufactured by selective laser melting. Eng. Fract. Mech. 120, 15-25 (2014).

18. Torrent, C. J. J. et al. On the microstructural and cyclic mechanical properties of pure iron processed by electron beam melting. Adv. Eng. Mater. 327, 2100018 (2021).

19. Witte, F. The history of biodegradable magnesium implants: a review. Acta Biomater. 6, 1680-1692 (2010).

20. Li, Y. et al. In vitro degradation and biocompatibility evaluation of typical biodegradable metals $(\mathrm{Mg} / \mathrm{Zn} / \mathrm{Fe})$ for the application of tracheobronchial stenosis. Bioact. Mater. 4, 114-119 (2019).

21. Zheng, Y. F., Gu, X. N. \& Witte, F. Biodegradable metals. Mater. Sci. Eng. R. Rep. 77, 1-34 (2014).

22. Li, H., Zheng, Y. \& Qin, L. Progress of biodegradable metals. Prog. Nat. Sci. 24, 414-422 (2014).

23. Waksman, R. et al. Short-term effects of biocorrodible iron stents in porcine coronary arteries. J. Interv. Cardiol. 21, 15-20 (2008). 
24. Peuster, M. et al. A novel approach to temporary stenting: degradable cardiovascular stents produced from corrodible metal-results 6-18 months after implantation into New Zealand white rabbits. Heart 86, 563-569 (2001).

25. Schinhammer, M., Hänzi, A. C., Löffler, J. F. \& Uggowitzer, P. J. Design strategy for biodegradable Fe-based alloys for medical applications. Acta Biomater. 6, 1705-1713 (2010).

26. Francis, A., Yang, Y., Virtanen, S. \& Boccaccini, A. R. Iron and iron-based alloys for temporary cardiovascular applications. J. Mater. Sci. Mater. Med. 26, 138 (2015).

27. Hufenbach, J., Wendrock, H., Kochta, F., Kühn, U. \& Gebert, A. Novel biodegradable Fe-Mn-C-S alloy with superior mechanical and corrosion properties. Mater. Lett. 186, 330-333 (2017).

28. Hufenbach, J. et al. Effect of Selective Laser Melting on Microstructure, Mechanical, and Corrosion Properties of Biodegradable FeMnCS for Implant Applications. Adv. Eng. Mater. 22, 2000182 (2020).

29. Lin, W. et al. In vivo degradation and endothelialization of an iron bioresorbable scaffold. Bioact. Mater. 6, 1028-1039 (2021).

30. Nie, F. L., Zheng, Y. F., Wei, S. C., Hu, C. \& Yang, G. In vitro corrosion, cytotoxicity and hemocompatibility of bulk nanocrystalline pure iron. Biomed. Mater. 5, 65015 (2010).

31. Moravej, M., Purnama, A., Fiset, M., Couet, J. \& Mantovani, D. Electroformed pure iron as a new biomaterial for degradable stents: in vitro degradation and preliminary cell viability studies. Acta Biomater. 6, 1843-1851 (2010).

32. Wegener, B. et al. Development of a novel biodegradable porous iron-based implant for bone replacement. Sci. Rep. 10, 9141 (2020).

33. Li, Y. et al. Corrosion fatigue behavior of additively manufactured biodegradable porous iron. Corros. Sci. 156, 106-116 (2019).

34. Li, Y. et al. Additively manufactured biodegradable porous iron. Acta Biomater. 77, 380-393 (2018).

35. Murr, L. E. \& Li, S. Electron-beam additive manufacturing of high-temperature metals. MRS Bull. 41, 752-757 (2016).

36. Hansen, N. Hall-Petch relation and boundary strengthening. Scr. Mater. 51, 801-806 (2004).

37. Torrent, C. J. J., Krooß, P. \& Niendorf, T. On the impact of build envelope sizes on E-PBF processed pure iron. Metall. Mater. Trans. B 31, 931 (2021).

38. Bruder, E. Mechanical properties of $\mathrm{ARMCO}^{\circledR}$ Iron after large and severe plastic deformation-application potential for precursors to ultrafine grained microstructures. Metals 8, 191 (2018).

39. Hu, Y. N. et al. The effect of manufacturing defects on the fatigue life of selective laser melted Ti-6Al-4V structures. Mater. Des. 192, 108708 (2020).

40. Vayssette, B., Saintier, N., Brugger, C., El May, M. \& Pessard, E. Numerical modelling of surface roughness effect on the fatigue behavior of Ti-6Al-4V obtained by additive manufacturing. Int. J. Fatigue 123, 180-195 (2019).

41. Tammas-Williams, S. et al. XCT analysis of the influence of melt strategies on defect population in Ti-6Al-4V components manufactured by Selective Electron Beam Melting. Mater. Charact. 102, 47-61 (2015).

42. Atapour, M., Wang, X., Färnlund, K., Odnevall Wallinder, I. \& Hedberg, Y. Corrosion and metal release investigations of selective laser melted $316 \mathrm{~L}$ stainless steel in a synthetic physiological fluid containing proteins and in diluted hydrochloric acid. Electrochim. Acta 354, 136748 (2020).

43. Cieślik, M., Engvall, K., Pan, J. \& Kotarba, A. Silane-parylene coating for improving corrosion resistance of stainless steel $316 \mathrm{~L}$ implant material. Corros. Sci. 53, 296-301 (2011).

44. Feliu, S. Electrochemical impedance spectroscopy for the measurement of the corrosion rate of magnesium alloys: brief review and challenges. Metals 10, 775 (2020).

45. Yamashita, T. \& Hayes, P. Analysis of XPS spectra of $\mathrm{Fe}^{2+}$ and $\mathrm{Fe}^{3+}$ ions in oxide materials. Appl. Surf. Sci. 254, 2441-2449 (2008).

46. Biesinger, M. C. et al. Resolving surface chemical states in XPS analysis of first row transition metals, oxides and hydroxides: $\mathrm{Cr}, \mathrm{Mn}, \mathrm{Fe}, \mathrm{Co}$ and $\mathrm{Ni}$. Appl. Surf. Sci. 257, 2717-2730 (2011).

47. Grosvenor, A. P., Kobe, B. A. \& McIntyre, N. S. Studies of the oxidation of iron by water vapour using $X$-ray photoelectron spectroscopy and QUASES ${ }^{\mathrm{TM}}$. Surf. Sci. 572, 217-227 (2004).

48. Lejček, P. et al. Selective laser melting of pure iron: multiscale characterization of hierarchical microstructure. Mater. Charact. 154, 222-232 (2019).

49. Günther, J. et al. Design of novel materials for additive manufacturing-isotropic microstructure and high defect tolerance. Sci. Rep. 8, 1298 (2018).

50. Mughrabi, H. \& Höppel, H. Werner Cyclic deformation and fatigue properties of very fine-grained metals and alloys. Int. J. Fatigue 32, 1413-1427 (2010).

51. Vaidya, W. V. et al. Improving interfacial properties of a laser beam welded dissimilar joint of aluminium AA6056 and titanium Ti6Al4V for aeronautical applications. J. Mater. Sci. 45, 6242-6254 (2010).

52. Gaytan, S. M. et al. Advanced metal powder based manufacturing of complex components by electron beam melting. Mater. Technol. 24, 180-190 (2009).
53. Tang, M., Pistorius, P., Chris \& Beuth, J. L. Prediction of lack-of-fusion porosity for powder bed fusion. Addit. Manuf. 14, 39-48 (2017).

54. Ralston, K. D. \& Birbilis, N. Effect of Grain Size on Corrosion: A Review. Corrosion 66, 075005-075005-13 (2010).

55. Chou, D.-T. et al. Novel processing of iron-manganese alloy-based biomaterials by inkjet 3-D printing. Acta Biomater. 9, 8593-8603 (2013).

56. Liu, B. \& Zheng, Y. F. Effects of alloying elements ( $M n, C o, A l, W, S n, B, C$ and S) on biodegradability and in vitro biocompatibility of pure iron. Acta Biomater. 7 1407-1420 (2011).

57. Li, J., Jiang, Q., Sun, H. \& Li, Y. Effect of heat treatment on corrosion behavior of AZ63 magnesium alloy in 3.5 wt.\% sodium chloride solution. Corros. Sci. 111 288-301 (2016).

58. Li, Z., Gu, X., Lou, S. \& Zheng, Y. The development of binary Mg-Ca alloys for use as biodegradable materials within bone. Biomaterials 29, 1329-1344 (2008).

59. Ralston, K. D., Fabijanic, D. \& Birbilis, N. Effect of grain size on corrosion of high purity aluminium. Electrochim. Acta 56, 1729-1736 (2011).

60. Gong, H., Wang, K., Strich, R. \& Zhou, J. G. In vitro biodegradation behavior, mechanical properties, and cytotoxicity of biodegradable $\mathrm{Zn}-\mathrm{Mg}$ alloy. J. Biomed. Mater. Res. Part B Appl. Biomater. 103, 1632-1640 (2015).

61. Teoh, S. Fatigue of biomaterials: a review. Int. J. Fatigue 22, 825-837 (2000).

62. Oyane, A. et al. Preparation and assessment of revised simulated body fluids. $J$. Biomed. Mater. Res. A 65, 188-195 (2003).

\section{ACKNOWLEDGEMENTS}

The authors thank the German Research Foundation (DFG) for the financial support of this study within the project "Einstellung von Mikrostruktur und Degradationsverhalten oxidpartikel-modifizierter Fe-Legierungen durch selektives Elektronenstrahlschmelzen“, grant number 413259151.

\section{AUTHOR CONTRIBUTIONS}

S.W. was responsible for fatigue life investigation and writing of the paper. C.J.J.T. did the additive manufacturing and the investigation of the microstructure. C.E. and M.V. did the chemical analytics. S.H. and P.K. helped to interpret the experimental data. G.G, T.N., F.N., and H.J.M.: conceptualization, review, and supervision of the study.

\section{FUNDING}

Open Access funding enabled and organized by Projekt DEAL.

\section{COMPETING INTERESTS}

The authors declare no competing interests.

\section{ADDITIONAL INFORMATION}

Correspondence and requests for materials should be addressed to Steffen Wackenrohr.

Reprints and permission information is available at http://www.nature.com/ reprints

Publisher's note Springer Nature remains neutral with regard to jurisdictional claims in published maps and institutional affiliations.

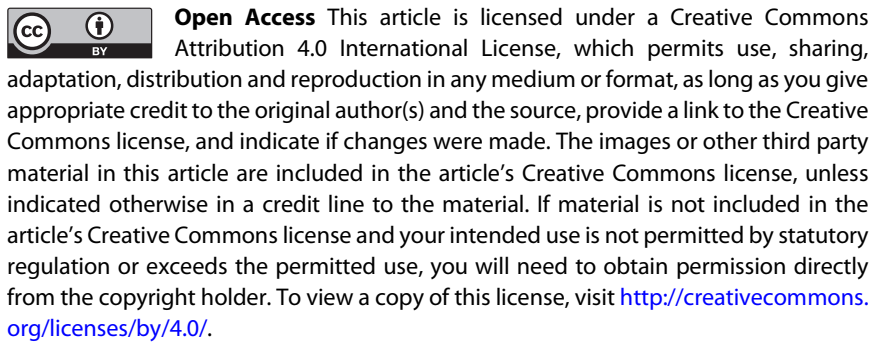

(c) The Author(s) 2022 